\title{
Current Trends in Second Language Assessment
}

\author{
Soo Hyoung Joo \\ Teachers College, Columbia University
}

The field of second language (L2) assessment has continued to evolve since the 1960s, broadening the scope of inquiry and adopting more sophisticated research methods (Chen, 2011; Kunnan, 2014). Technological innovations have allowed wider application of tools for assessment design, development, and analysis (Purpura \& Banerjee, 2021). In addition to the quantitative methods, the qualitative methods have also been widely adopted, providing more meaningful information not only about the test takers' L2 proficiency but also the role assessment played on teaching and learning.

This forum attempts to showcase these trends with a focus on diverse methods of analysis. In particular, Mahshad Davoodifard investigates the application of technology in the scoring process of writing. She adopts Natural Language Processing (NLP) to develop an automated plagiarism detection model and reports her process of designing and testing out a plagiarism detection algorithm comparing the lexical features between the suspicious documents and the source documents.

Daniel Eskin, on the other hand, uses Multivariate Generalizability Theory (MG-theory) analysis to provide empirical backing for two inferences from Kane's Argument-based approach to Validation framework (Kane, 2006). First, he attempts to support the generalizability inference, investigating whether a placement test writing section consistently classifies the test takers based on a predetermined cut-score. He examines the sources of score variability (e.g., task difficulty, rating severity, rubric functionality) and the overall dependability of test data. Second, he provides support to the utilization inference, examining whether the rubric as well as the number of tasks and ratings are appropriate for all stakeholders.

Finally, Kimberly Tan focuses on classroom-based assessments which has a primary role of supporting teaching and learning. She analyses a stretch of classroom discourse to examine spontaneous assessment mediated through peer-to-peer interaction using the seven dimensions in the Learning-Oriented Assessment (LOA) framework. She examines whether assessment contributed or hindered L2 processing and learning.

While these papers on three distinct topics show the widening range in research areas and approaches in the field of L2 assessment, they also show what the field strives for, which is to make better inferences about the test-takers' ability, and to use this information to ultimately benefit teaching and learning.

\section{REFERENCES}

Chen, J. (2011). Language assessment: Its development and future-An interview with Lyle F. Bachman. Language Assessment Quarterly, 8(3), 277-290.

(C) 2022 Joo. This is an open access article distributed under the terms of the Creative Commons Attribution License, which permits the user to copy, distribute, and transmit the work provided that the original authors and source are credited. 
Kane, M. (2006). Validation. In R. Brennan (Ed.), Educational measurement (4th ed., pp. 1764). American Council on Education and Praeger.

Kunnan, A. J. (2014). Looking back and looking ahead: LAQ 10 years on. Language Assessment Quarterly, 11(1), 1-4.

Purpura, J. E., \& Banerjee, H. L. (2021, June). The Affordances of Scenario-Based Assessment for Measuring 21st Century Language-Driven Competencies. Paper presented at 2021 LTRC annual conference symposium "Rethinking Second Language Proficiency Assessment Using a Scenario-Based Assessment Approach: Opportunities and Challenges." Virtual.

Soo Hyoung Joo is a doctoral student in Applied Linguistics at Teachers College, Columbia University. Her research interest includes assessing 21C competencies through scenario-based language assessment and the role of feedback in learning-oriented assessment. Correspondence should be sent to E-mail: shj2118@tc.columbia.edu 